\title{
Periodistas pioneras e innovadoras en la historia de la televisión en España: Blanca Álvarez y Lolo Rico
}

\author{
María Gallego Reguera \\ Universidad Internacional Menéndez Pelayo \\ Next International Business School \\ mariagalle@gmail.com
}

Recibido: 29 de mayo de 2016

Aceptado: 26 de junio de 2016

\section{Resumen}

Este artículo tiene como objetivo mostrar la aportación profesional a la historia de la televisión en España de las periodistas Blanca Álvarez y Lolo Rico. Ambas fueron pioneras y realizaron una labor innovadora como creadoras de contenido y directivas, contribuyendo así al desarrollo del recién nacido ente público RTVE. Tras el análisis de sus trayectorias profesionales, se reflejarán los procesos de empoderamiento en un medio, la televisión, y en una profesión, el periodismo, con profundas raíces patriarcales.

Palabras clave: Televisión; RTVE; producción audiovisual; periodismo; comunicación; mujeres.

Pioneering and innovative journalists in the history of television in Spain: Blanca Álvarez and Lolo Rico

\begin{abstract}
This paper aims to show professional contribution to the history of Spanish television by two journalists Blanca Alvarez and Lolo Rico. Both of them were pioneers and made an innovative contribution to the development of the new public entity RTVE as creators of content and managers. Analyzing their careers, we will observe the empowerment processes in a medium (television), and in a profession (journalism), with deep patriarchal basis.
\end{abstract}

Keywords: Television; RTVE; Audiovisual Production; Journalism; Communication, Women.

\section{Referencia normalizada}

Gallego Reguera, M. (2016). Periodistas pioneras e innovadoras en la historia de la televisión en España: Blanca Álvarez y Lolo Rico. Historia y Comunicación Social. Vol 21, número 2, páginas 487-496.

Sumario: 1. Introducción. 2. Periodistas y televisión. 3. Blanca Álvarez, directiva pionera de TVE. 3. Lolo Rico, creadora innovadora. 5. Conclusiones. 6. Referencias bibliográficas. 


\section{Introducción}

La historia de la televisión en España no se escapa de la generalizada tendencia de ocultación de las aportaciones de las mujeres a la historia de la humanidad (Nash, 2004) Aunque, desde los inicios de la televisión, a partir de 1956, las periodistas han sido protagonistas de la creación y el desarrollo de este medio de comunicación, encontramos una invisibilización sistemática (Tajahuerce Ángel, 2011), que pasa también por encasillamiento en géneros menores, de sus logros profesionales (Lauzen, 2012).

La televisión como industria cultural ha contribuido, desde su nacimiento, a perpetuar los roles y estereotipos patriarcales. Las periodistas pioneras en este medio de comunicación comenzaron su andadura de forma precaria, ya que la puesta en marcha de la televisión en España se produjo en plena dictadura franquista. Esta situación política significará para las mujeres el retorno a la esfera privada y sus relaciones laborales estarán condicionadas, hasta la ley de relaciones laborales de 1976, a "la exigencia de la autorización marital para el ejercicio de los derechos laborales" (Folguera Crespo, 1997:543).

En la televisión española, observamos que las periodistas accedieron antes a realizar "pantalla", que a las redacciones (García-Albi, 2007:141). Ese fue el caso de Blanca Álvarez, que comenzó como presentadora para pasar desarrollar su labor profesional detrás de las cámaras y convertirse así en directiva y gestora dentro del ente público. Bajo su mandato, se importaron y adaptaron series de gran éxito como Érase una vez o Barrio Sésamo. Por su parte, Lolo Rico accedió a la televisión como guionista y su gran aportación fue la creación y dirección del innovador programa $\mathrm{La}$ bola de cristal.

En este artículo se analizan las trayectorias profesionales de ambas periodistas, que iniciaron su carrera en los albores de la televisión pública, rompiendo barreras y realizando una interesante aportación a la historia del medio en España.

\section{Periodistas y televisión}

Para el estudio de las aportaciones profesionales de las periodistas analizadas en este estudio, es necesaria una breve contextualización histórica sobre la omnipresente relación, a todos los niveles, entre la televisión y el poder. La historia de la televisión pública en España está profundamente marcada por su vinculación al poder político, y esta característica condicionará, indudablemente, la labor de sus periodistas. Las constantes presiones de la censura franquista sobrevivirán durante la democracia, siempre al servicio del gobierno de turno. Aunque, es preciso destacar el papel fundamental que tuvo la televisión, en el proceso de transición política, como elemento cohesionador de la sociedad a favor de la democracia, y en su máxima expresión con la emisión del mensaje del Rey tras el intento de golpe de Estado en 1981.

Ya en democracia, el primer Gobierno socialista, liderado por Felipe González, instrumentalizará la televisión pública durante sus catorce años de mandato (Fernán- 
dez \& Santana, 2000:285). Al igual que lo harán, en mayor o menor medida, los gobiernos sucesivos hasta nuestros días. Un claro ejemplo de este control mediático fue experimentado por Lolo Rico, quien recibió mensajes para que no se posicionara en contra de la OTAN a través de su exitoso programa juvenil La bola de cristal.

La apertura política permitirá a las periodistas alcanzar mayores cuotas de libertad y también de poder, pero el camino será arduo y lento, y se va a prolongar hasta nuestros días. Mientras los puestos de dirección se mantendrán bajo el dominio mayoritario de los varones, las periodistas serán mayoría en las aulas universitarias (Rivero Santamarina, et al., 2015) y accederán en masa a las redacciones, en la medida en que el trabajo periodístico se vaya precarizando. La devaluación de la televisión como medio de comunicación significará una feminización de sus trabajos, ya que "las trabajadoras no están ascendiendo al nivel de sus compañeros, sino que la mayor parte de éstos han sido descendidos al nivel de aquéllas" (Castells, 2009:59). En este proceso industrial de producción televisiva, las periodistas también se van a encontrar, en sus deseos de ascenso, con "el techo de cristal" (Loughran \& McDonald, 2015), definido por Amorós (2007:392) como "la desestimación sistemática de las mujeres en los sistemas de cooptación que operan en la selección de los puestos de más alta capacidad de decisión".

La producción profesional de las dos periodistas analizadas en este trabajo se inicia en los albores de la televisión y se desarrolla fundamentalmente hasta la década de los noventa, cuando se romperá el monopolio de la televisión pública con la llegada de las privadas. Estos trabajos se desarrollaron en Madrid, en un principio desde los precarios estudios del Paseo de la Habana y, a partir de 1964, en los estudios Prado del Rey. En este periodo, la televisión se convirtió rápidamente en un medio popular y accesible para la mayor parte de la sociedad.

Durante la etapa analizada, se produjeron grandes hitos tecnológicos en el medio, que condicionaron los procesos de producción de sus periodistas. El monopolio audiovisual, la bonanza económica y la doble vía financiación del ente (a través de subvenciones y publicidad) facilitaron la expansión de la televisión pública, que se hizo patente con la puesta en marcha en 1966 de la segunda cadena, denominada en un principio UHF. La televisión se convirtió así en el medio de comunicación más popular y en la industria cultural con más inversión y presupuesto.

Es reseñable el cambio legislativo que se produjo en 1966 para el periodismo español. La Ley de Prensa e Imprenta, conocida como "Ley Fraga", va a eliminar formalmente la censura previa en un intento de apertura informativa. A partir de entonces, en un marco de paulatina libertad política hacia la democracia, se observará cómo la labor del periodismo televisivo se convertirá en fundamental en la construcción del poder y el contrapoder político.

Siguiendo el planteamiento de Bernárdez Rodal (2015), resulta fundamental recuperar el trabajo que las mujeres realizaron en los medios de comunicación, para dejar clara constancia de su aportación profesional a la historia. En esa línea, el presente artículo tiene como principal objetivo reconstruir la experiencia de las periodistas 
Blanca Álvarez y Lolo Rico, a través de una metodología basada en los métodos cualitativos de la observación y lectura. Ha resultado indispensable en esta investigación el análisis del discurso de sus testimonios orales y escritos, recopilados a través de bibliografía especializada y entrevistas.

Este texto pretende reconstruir sus currículos profesionales para observar y analizar la participación y su evolución en la historia del medio. Hay que tener en cuenta que la variada bibliografía existente sobre la historia de la televisión en España no llega a reflejar con justicia, y mucho menos con detalle, la importancia de la obra profesional de las periodistas citadas. Como una de las excepciones, destaca en esta labor de visibilización la obra publicada por Díaz (1994) sobre la historia de la televisión, pero esta tendencia no abunda en el resto de las referencias bibliográficas sobre la materia. Por eso, se ha optado por el análisis del discurso en documentos que citan sus propias palabras, como reseñas biográficas y autobiografías, para poder obtener información ocultada o minimizada en otro tipo de publicaciones más genéricas, limitadas, politizadas o simplemente sesgadas.

Este estudio refleja también una selección de artículos publicados en prensa y revistas, que han aportado luz sobre algunas fechas, nombres de programas o datos concretos, que se relatan a lo largo del mismo. Se ha prestado especial atención a temas fundamentales de las trayectorias vitales de las profesionales, como son: los estudios cursados, el contexto social y su producción profesional. Resulta de especial importancia, en este texto, la observación del proceso de empoderamiento de las periodistas y la gestión de los conflictos a los que se enfrentaron a lo largo de sus respectivas carreras.

\section{Blanca Álvarez, directiva pionera de TVE}

Blanca Álvarez (1931-2000) llegó a Televisión Española el 2 de febrero de 1957 y pronto se convirtió una presentadora estrella, junto a otros profesionales como Jesús Álvarez, Laura Valenzuela, Paco Valladares, María Jesús Valero o David Cubedo. Tras ser alejada de las pantallas por su maternidad, luchó por continuar trabajando detrás de la cámara y llegó a convertirse en directiva y productora ejecutiva del ente público. Aterrizó en la profesión de la mano de su padre, un periodista taurino, a quien acompañaba a tertulias con otros periodistas, actores y toreros (El País, 2000). Esta experiencia de su juventud sembró la vocación que logró materializar al diplomarse en la Escuela de Periodismo en 1958. Aunque, sus primeros pasos los dio mucho antes, escribieron para revistas juveniles como Umbral, Alba, Tin Tan y Volad, entre 1950 y 1955 . Después, comenzó a colaborar en los periódicos Madrid y Pueblo.

Mientras estudiaba, Blanca Álvarez se presentó a las pruebas de TVE para locutoras, no sin antes pedir permiso a su pareja como imponía la época (Díaz, 1994:158). TVE fichó a Blanca Álvarez en 1957 como presentadora de programas de variedades, para los que ella también redactaba sus propios textos, lo que sin duda le hizo destacar sobre el resto. En aquella época, era común improvisar cuñas publicitarias y llenar 
tiempos muertos sin guión previo. Pronto se convirtió en una estrella de televisión, pero al contrario de lo que se podría imaginar, su trabajo no estaba bien remunerado económicamente. Ella misma lo llegó a denunciar: "Trabajaba como una negra, como una proletaria más, vivía en el barrio de San Blas, en aquellas casas que hizo Franco y que salían en el NO-DO. Una estrella de la TV y vivía en San Blas y ganaba 2.500 pesetas al mes" (Díaz, 1994:153).

La periodista tenía que compatibilizar su trabajo en la televisión con el cuidado de siete hijos, lo que condicionaba su permanencia como presentadora, ya que era retirada de pantalla cada vez que se quedaba embarazada. Ante esta situación, comenzó a trabajar también detrás de las cámaras y asumió otras responsabilidades en la cadena pública como jefa de la Secretaría Técnica de Programas, realizando un trabajo que ella misma denominó "engorroso" y "lleno de problemas" (Díaz, 1994:153). En aquella etapa, seguía conectada al periodismo, colaborando en la redacción de la revista del ente Tele Radio, desde 1958 hasta 1965.

A partir de 1968, trabajará estrechamente con Adolfo Suárez, recién nombrado jefe de Programas. Ese mismo año, falleció el marido de la periodista, lo que supuso un duro golpe para la numerosa familia. Dentro de televisión, contará con el apoyo de Adolfo Suárez y de Pepe Casas, quien le ofreció presentar y dirigir el programa Consulte a su médico, mientras continuaba como responsable de la Secretaría Técnica de Programas. En aquella época, ya contaba con suficiente experiencia y había dirigido, con anterioridad, un programa económico denominado Nivel de Vida.

Más tarde, y bajo el mandato de Fernández de Asís, Blanca Álvarez pasó al Departamento de Guiones y Programación y, de 1970 hasta 1974, se convirtió en la directora de Programas Infantiles y Juveniles. Así, comenzó una nueva etapa profesional que la llevará a viajar al extranjero para buscar nuevos formatos de televisión. Es destacable la interesante programación que realizó en esta época con formatos entre los que se encontraban: Erase una vez, A cinco años vista, La Casa del Reloj y Los Chipirifláuticos.

Al tomar una posición de poder en TVE, Blanca Álvarez comenzó a tener problemas. Según ella misma relataba, por entonces, "al señor Salvador Pons le molesta que una señora sea jefa de programas y comienza a darle la tabarra a Luis Ezcurra, en las reuniones de dirección que tienen, para que me destituya" (Díaz, 1994:156). Con esta oposición a su mandato, finalmente se ve arrastrada al Instituto de Radio Televisión Española, en una especie de retiro profesional.

Ante esta nueva situación, la periodista no sucumbió y continuó luchando por ejercer su profesión y volver a la primera línea de televisión, así que se propuso realizar la serie La aventuras del hada Rebeca. Regresó al medio con el encargo de viajar a Estados Unidos para contratar y adaptar la serie Barrio Sésamo, lo que supuso un éxito total en televisión. También realizó otras conocidas adaptaciones de programas como 3,2,1..., Contacto (un espacio para jóvenes sobre ciencia) o Pipicalzaslargas. 
La periodista siempre tuvo una especial conciencia de género, y así lo transmitió: "especialmente mirábamos con lupa el tratamiento digno de los personajes femeninos, no solo para lo que comprábamos fuera, sino también para lo que creábamos aquí" (Martínez Álvarez, 2010:46). Es importante señalar que fue decisión de Blanca Álvarez contar para la programación infantil de TVE con Lolo Rico, para que colaborara como directora en una segunda fase del programa infantil La cometa blanca.

Blanca Álvarez también realizó carrera como docente, en la Escuela Oficial de Periodismo (1966-68), en el Instituto de RTVE (1972) y en la Universidad (19751977). Se mantuvo en activo en TVE hasta los años 90, encargándose de las pruebas de balonmano y gimnasia rítmica en las Olimpiadas Barcelona'92. También formó parte como vocal en las juntas directivas de la Academia de las Ciencias y las Artes de Televisión y de la Asociación de la Prensa de Madrid. Falleció en el año 2000. Muchos la recuerdan por sus primeros años de trabajo, cuando salía por televisión. "Casi 36 años he trabajado en esta casa y lo que menos he hecho ha sido pantalla, aunque es por esto por lo que se me conoce", se llegó a lamentar en su día la propia periodista (Díaz, 1994:156).

\section{Lolo Rico, creadora innovadora}

Lolo Rico (1935) fue la creadora y directora de uno de los programas más innovadores de la televisión en España: La bola de cristal (1984). Inició unos estudios de Bellas Artes que no finalizó y, después, se interesó por la escritura y la literatura. Por eso, se matriculó en Periodismo y logró titularse estudiando por las noches, mientras cuidaba a sus hijos. Al igual que Blanca Álvarez, fue madre de familia numerosa, tuvo siete hijos, a los que cuidó sola, como ella misma ha escrito: "Tener tantos hijos fue un capricho, una arbitrariedad de mi marido, que tuvo siempre una vana inclinación por batir su propio récord (...) aunque no se ocupara de ellos y los cogiera en brazos solo el día del bautizo" (Rico, 2008:154). Años más tarde, se separó y se quedó a cargo de sus hijos, en una situación precaria. Ante las dificultades familiares y económicas, encontró en su pasión por la escritura su medio de vida.

Empezó colaborando en la revista Vallecas, con artículos vinculados al mundo de la mujer, es decir, al hogar, la vida familiar y la educación de los hijos. También, realizó sus pinitos en televisión con pequeños guiones que ella misma proponía. Así, convirtió su libro infantil Se vende Villacañitas, publicado por Anaya, en un programa de televisión. Después de su primer éxito televisivo, le llegó el encargo de una serie compuesta por nueve guiones. Aunque era ella quien los escribía, su marido se empeñaba en supervisar sus textos: "Mi marido se sentaba conmigo como un maestro con su discípulo para dictarme o escribir el mismo escenas cursis, ridículas o falsas o aberrantes, que yo debía elogiar para no suscitar problemas, y luego camuflar" (Rico, 2008:156).

La periodista provenía del mundo de los cuentos, la fantasía y la escritura, pero no tenía formación audiovisual, ni cinematográfica. Por eso, al empezar a recibir peticio- 
nes de TVE, se convirtió en una autodidacta audiovisual. Así lo narra en sus memorias: "En cuanto empecé a mirar la televisión como un aprendizaje, en cuanto cerré los ojos y empecé a mirar lo que quería ver en pantalla cuando saliera mi programa, entendí que me dedicaría a la imagen" (Rico, 2008:158). Aprendió rápido y su trabajo fue bien recibido en televisión, por eso le encargaron los guiones de otro programa infantil para TVE, denominado La casa del reloj, para el que también escribía letras de canciones.

Lolo Rico se ha declarado públicamente como una mujer de izquierdas y feminista. Siempre fue una mujer combativa, que luchó por sus creencias. Siguiendo la ideología marxista, en la década de los setenta, ingresó junto a muchos otros intelectuales de la época en el Partido Comunista. A finales de esa misma década (1979), Lolo Rico se encontraba en una situación económica complicada. Dependía de ella una familia numerosa y necesitó de varios trabajos para obtener ingresos suficientes. Colaboraba en Radio Nacional de España, mientras hacía sus pinitos como editora en Bruguera y preparaba el programa La cometa blanca.

Su gran oportunidad llegó en 1984, cuando le ofrecieron dirigir un programa infantil semanal, un nuevo proyecto que ella convirtió en La bola de cristal. Resulto ser uno de los programas más innovadores de la historia de la televisión en España. Con un claro trasfondo marxista, el programa supo captar la vanguardia y retrató de forma fiel la estética de la "Movida Madrileña", que por aquel entonces despuntaba en la capital. Tal y como recuerda la periodista: "Tenía dos ideas claras: hacer algo novedoso y tener un equipo creativo. Éramos de izquierdas, nuestra crítica estaba teñida de marxismo y tamizada con un gran sentido del humor" (Gallego Reguera \& González Irureta-Goyena, 2011). Para el asesoramiento musical, Lolo Rico contó con su peluquero, Carlos Núñez, quien le presentó a los artistas del momento.

Pronto conoció a Carlos Juan Casado, director de Virgin en España y del RockOla, una sala de referencia de la "Movida". "Gracias a él conocí el mundo de la música pop (...) Me puso en contacto con grupos, me orientó sobre la modernidad y dio el visto bueno a la parte musical de La bola de cristal" (Rico, 2008:299). Este programa fue desde sus inicios provocador y combativo. Apostó por la emisión de series extranjeras, que tuvieron una gran aceptación por parte del público, como fueron La pandilla, La familia Monster o Embrujada. Este programa juvenil pronto se convirtió en un espacio de libertad donde se proclamaban frases como " $i V i v a$ el mal, viva el capital! ¡Viva la economía, viva la CIA!”.

Por ejemplo, cuando llegó el Referéndum de la OTAN, la directora del programa recibió una llamada del director de la primera cadena, Gonzalo Vallejo, quien le pidió que no hiciera propaganda en contra de la OTAN en su programa (Rico, 2011). Ella no quería traicionar a su director, pero tampoco a su ideología, así que encontró una original forma de salirse con la suya. Junto a su equipo, decidió emitir unas imágenes, tomadas desde un helicóptero, de un grupo de personas cuya formación decía "OTANO". La directora pasó los siguientes días esquivando a los altos cargos de la cadena, pero nadie se lo reprochó. 
En aquella ocasión se libró, pero después llegaría una petición de censura que supuso el final del mítico programa. Su equipo de guionistas había preparado un gag que ridiculizaba la enseñanza privada a favor de la pública. Desde la dirección de la cadena le pidieron a la directora que cortara esas imágenes. Lolo Rico pidió por escrito una orden de corte por parte de la dirección que nunca recibió, así que decidió no cortar la secuencia del programa. Muy a su pesar, en TVE decidieron suprimir las imágenes sin su permiso. Por esta razón, Lolo Rico presentó su dimisión ante Pilar Miró, como directora general, aunque ella no la aceptó y llegaron a un acuerdo para que Rico terminara la temporada del programa antes de abandonar el proyecto. En compensación, le ofrecieron un programa de crítica política que tituló Los Pepones y cuya emisión fue frustrada por el siguiente director del ente público, Luis Solana, quien no consideraba adecuado el carácter comprometido de sus contenidos ante las elecciones generales y autonómicas. Después de este episodio, Lolo Rico solicitó una excedencia.

Regresó a la televisión bajo el mandato de Ramón Colom como director general y en 1991 fue nombrada directora del área de Programas Infantiles y Juveniles, puesto que había ocupado Blanca Álvarez con anterioridad. Para realizar esta labor, decidió no interrumpir su excedencia y acceder al puesto a través de un contrato de personal externo. La periodista se encontró, de nuevo, con problemas en TVE. Al asumir su nuevo cargo, se veía obligada a emitir programas que TVE había firmado con anterioridad a su contrato y con los que ella no estaba de acuerdo. Al final, logró imponer su criterio con algunos espacios como fueron Los Bu, Pasando y No te cortes. También desde la dirección general limitaron sus fichajes para presentadores. Así lo explicó ella misma: "La dirección elaboró su propio programa de acoso y derribo contra mí. Volveríamos a los presentadores estereotipados: tías buenas que gustaran a los papás y chicos de apariencia tranquilizadora" (Rico, 2008:315).

Después de este breve e infructuoso episodio televisivo, que terminó con otra solicitud de excedencia en 1992, Rico decidió presentar una denuncia ante el Senado sobre los problemas que presentaba TVE para los niños y jóvenes, pero no contó con apoyo. Cuando terminó su periodo de excedencia en TVE, decidió volver, aunque no la quisieron readmitir, así que tuvo que ir a un juicio que finalmente ganó. Al regresar, le ofrecieron dos opciones: renunciar a los atrasos y conseguir un buen puesto o no hacerlo y ser desterrada a un puesto inferior. Como no aceptó las condiciones, fue desterrada a visionar películas en una cabina con la misión de comprobar las condiciones técnicas para su emisión. Esta tarea le produjo un desprendimiento de retina, por el que permaneció un año y medio de baja.

Volvió a ser llamada para trabajar en la televisión pública bajo el mandato del PP $\mathrm{y}$, en concreto, le pidieron una serie de documentales sobre personajes de ficción para el área de Cultura que dirigía por aquel entonces Rafael Martínez Durbán. Realizó tres: "La maestra" de Historia de una maestra, de Josefina Aldecoa; "Manuel", el preso de La oscura historia de la prima Montse, de Juan Marsé; y un programa sobre poemas de Bernardo Atxaga. Ninguno de estos programas se llegó a emitir. Cuando 
terminó su labor fue al despacho del director a por su siguiente encargo y se encontró una desagradable situación.

Fui al despacho del director de culturales para saber qué documental iba a grabar a continuación. Como estaba ocupado, el productor entró a preguntárselo. Yo me quedé en la secretaría, junto a la puerta, y pude oír que el director decía: "Dale lo que sea para que se entretenga". Comprendí que iba a trabajar inútilmente para que mis programas durmieran el sueño de los justos en un cajón y no salieran jamás en la pequeña pantalla, así que decidí marcharme y, guiada por un impulso, entré en el despacho y lo comuniqué. (Rico, 2008:320)

Así terminó la carrera televisiva de Lolo Rico, que se volcó profesionalmente en la literatura y en el estudio de los efectos de las imágenes en los espectadores. Fruto de estos años de trabajo publicó obras sobre el medio como TV, la fábrica de mentiras, El buen espectador o Ver y enseñar a ver televisión.

\section{Conclusiones}

Una vez estudiadas las trayectorias profesionales de Blanca Álvarez y Lolo Rico, se pueden observar ciertas similitudes. Ambas se desarrollaron profesionalmente en el área televisiva dedicada a mujeres y a jóvenes, géneros considerados menores en una época en la que las grandes apuestas se centraban en las adaptaciones televisivas de los autores clásicos. Tanto es así, que las dos ocuparon, en diferentes períodos, el mismo puesto de dirección de Programación Infantil y Juvenil de TVE.

Blanca Álvarez, que comenzó en los albores de la televisión pública como presentadora, en pleno franquismo, pronto destacó como directiva y fue la encargada realizar importantes adaptaciones de programas de gran repercusión como Érase una vez o Barrio Sésamo. Por su parte, Lolo Rico se inició como guionista y diseñó el innovador programa La bola de cristal, en la efervescente década de los ochenta.

A través del análisis de su discurso escrito y oral, se observan las dificultades a las que se enfrentaron en el ascenso a puestos directivos en televisión y las barreras que tuvieron que derribar en su camino para lograr sus objetivos profesionales. La maternidad supuso un condicionante importante para la carrera como presentadora de Blanca Álvarez, quien era retirada de pantalla cada vez que se quedaba embarazada. Por otra parte, también se encontró con la oposición a su gestión directiva detrás de las cámaras, simplemente por el hecho de ser mujer. Lolo Rico también se halló dificultades para desarrollar su carrera dentro su ámbito familiar, ya que se veía obligada a pasar los textos que escribía por la supervisión de su marido.

Al final de su trayectoria, Blanca Álvarez lamentó que solo se reconocieran sus breves años en pantalla, y no toda su labor como directiva en TVE. Por su parte, Lolo Rico decidió abandonar definitivamente la televisión, tras no ser admitidos ni reconocidos sus últimos trabajos, para dedicarse a la escritura. Como profesionales, asumieron sus responsabilidades y se rebelaron contra el poder, haciendo valer su criterio. Lolo Rico fue censurada y readmitida más tarde como directora del área infantil del 
ente público y Blanca Álvarez fue apartada durante una etapa de su carrera a una especie de retiro en el Instituto de Radio Televisión Española.

En general, se podría concluir, que sus trabajos y aportaciones han sufrido una ocultación o invisibilización, pasando a la historia, en el mejor de los casos, el nombre de sus obras, pero no el nombre de sus autoras. Es necesario destacar que las periodistas no solo realizaron una relevante aportación a la historia de la televisión en España, también rompieron barreras en un medio masculinizado y patriarcal, abriendo nuevos caminos y oportunidades para las siguientes generaciones.

\section{Referencias bibliográficas}

AMORÓS, C. (2007). La gran diferencia y sus pequeñas consecuencias... para las luchas de las mujeres. Madrid: Ediciones Cátedra.

BERNÁRDEZ RODAL, A. (2015). Mujeres en Medios (S): Propuestas para analizar la comunicación masiva con perspectiva de género. Madrid: Fundamentos.

CASTELLS, M. (2009). Comunicación y poder. Madrid: Alianza Editorial.

DÍAZ, L. (1994). La televisión en España. 1949-1995. Madrid: Alianza Editorial.

EL PAÍS (2000). Blanca Álvarez, pionera de Televisión Española. El País, 7 Julio.

FERNÁNDEZ, I. \& SANTANA, F. (2000). Estado y Medios de Comunicación en la España Democrática. Madrid: Alianza Ensayo.

FOLGUERA CRESPO, P. (1997). El franquismo. El retorno a la esfera privada (19391975). En: Historia de las Mujeres en España. Madrid: Síntesis, pp. 527-548.

GALLEGO REGUERA, M. \& GONZÁLEZ IRURETA-GOYENA, B. (2011). Tesoros Vivos de la Televisión. Academiatv. Revista de la Academia de las Ciencias y las Artes de Televisión., Issue 121, pp. 45-47.

GARCÍA-ALBI, I. (2007). Nosotras que contamos. Mujeres periodistas en España. España: Plaza Janés.

LAUZEN, M. M. (2012). Where Are the Film Directors (Who Happen to be Women)?. Quarterly Review of Film and Video, 29(4), pp. 310-319.

LOUGHRAN, T. \& MCDONALD, B. (2015). Old glass ceilings are hard to break: Gender usage trends in annual reports. Studies in Communication Sciences, 15(1), pp. 5-11.

MARTÍNEZ ÁlVAREZ, A. (2010). Diez años sin Blanca. Homenaje. Academiatv. Revista de la Academia de las Ciencias y las Artes de Televisión, Issue 115, pp. 44-46.

NASH, M. (2004). Mujeres en el mundo. Madrid: Alianza Editorial.

RICO, L. (2008). ¿Cómo es posible que el tiempo pase tan deprisa y yo no me dé cuenta? Lolo Rico. Memorias. Barcelona: Plaza Janés.

(2011). Tesoros Vivos de la Televisión [Entrevista] 2011.

RIVERO SANTAMARINA, D., MESO AYERDI, K. \& PEÑA FERNANDEZ, S. (2015). La feminización de los estudios de Periodismo: análisis del caso español. Revista Latina de Comunicación Social, Volumen 70, pp. 566-583.

TAJAHUERCE ÁNGEL, I. (2011). Prólogo. Historia y Comunicación Social, Volumen 16, pp. 7-10. 